\title{
5. ve 7. Sınıf Türkçe Ders Kitaplarında Somut Olmayan Kültürel Miras Unsurlar1
}

\author{
Doç. Dr. Derya Yıldız \\ Necmettin Erbakan Üniversitesi, \\ Ahmet Keleşoğlu Eğitim Fakültesi \\ Türkçe Eğitimi Ana Bilim Dalı \\ deryacintasyildiz@gmail.com
}

\author{
Doç. Dr. Dilek Ceran \\ Necmettin Erbakan Üniversitesi, \\ Ahmet Keleşoğlu Eğitim Fakültesi \\ Türkçe Eğitimi Ana Bilim Dalı \\ dlkcrn@yahoo.com
}

Öz

“Somut olmayan kültürel miras” terimi, UNESCO'nun “kültürel mirasın korunması” için yürüttüğü programlar sırasında ortaya çıkmıştır. UNESCO, somut olmayan kültürel mirası, özelde ait olduğu topluluğun genelde ise insanlığın ortak mirası olarak kabul eder. Somut olmayan kültürel mirasın korunması, bu değerlerin sürdürülebilir olmasına bağlıdır. $\mathrm{Bu}$ da somut olmayan kültürel mirasın genç kuşaklara anlatılmasını gerektirmektedir. Bu nedenle eğitim sistemlerinin kültürel mirası korumak için farkındalık oluşturmaları gerekmektedir. Bu çalışmanın amacını, 5. ve 7. sınıf Türkçe ders kitaplarında yer alan somut olmayan kültürel miras unsurlarının incelenmesi oluşturmaktadır. Araştırmada doküman incelemesi kullanılmıştır. Verilerden, gerektiğinde alıntılar yapılmıştır. UNESCO ile Kültür ve Turizm Bakanlığının Ulusal Envanterlerinde yer alan ve her iki sınıf kitabında yer alan unsurlar: Mevlevi Sema Töreni, Kırkpınar Yağlı Güreş Festivali, Dede Korkut Mirası: Destan, Masal ve Müzik, Türk Kahvesi Kültürü ve Geleneği; sadece 5. Sinıfta yer alan unsurlar: Alevi-Bektaşi Ritüeli: Semah, Âşıklık Geleneği, Geleneksel Çini Ustalığı; sadece 7. Sinıfta yer alan unsurlar: Ebru: Türk Kâğıt Süsleme Sanatı, Bahar Kutlaması: Hıdrellez'dir. Bulgulara göre Türkçe ders kitaplarında somut olmayan kültürel miras unsurlarına daha fazla yer verilmesi gerektiği belirtilebilir.

Anahtar Kelimeler: Somut olmayan kültürel miras, Türkçe eğitimi, Türkçe ders kitapları, UNESCO, envanter.

\section{Intangible Cultural Heritage Elements in Turkish Language Course Books of Grade 5 and Grade 7}

\begin{abstract}
The term "intangible cultural heritage" emerged during the programs conducted by UNESCO for "the safeguarding of cultural heritage". UNESCO visualises intangible cultural heritage as the common memory of primarily the society that creates and safeguards it and then the whole humanity. Safeguarding of intangible cultural heritage would be possible by making this heritage sustainable. Therefore, educational systems should show the young generations the significance of cultural heritages and create awareness to safeguard cultural heritage. The main purpose of this study is to investigate elements of intangible cultural


heritage included in Turkish language course books of grades 5 and 7 . The study is a qualitative research, and it has been evaluated using the document review method. When it was necessary, the findings examined in the research were directly quoted. The elements which are inscribed in the UNESCO Intangible Cultural Heritage Lists and Inventories of the Ministry of Culture and Tourism, and included in the course books of both grades are: The Mevlevi Sema Ceremony, The Kirkpınar Oil Wrestling -Festival, The Heritage of Dede Qorqud: Epic Culture, Folk Tales and Music, Turkish Coffee Culture and Tradition; in only grade 5 are: Alevi-Bektaşi Ritual, Semah, The Aşıklık Tradition, Traditional craftsmanship of Çini-making; only grade 7 are: Ebru, Turkish art of marbling, The Spring Celebration: Hidrellez. In reference to the findings, it can be concluded that Turkish language course books should be enriched with texts involving more expressions related to intangible cultural values.

Keywords: Intangible cultural heritage, Turkish education, Turkish course books, UNESCO, inventory. 


\section{GİRIŞ}

Toplumlarda aidiyet duygusu kültürel miras aracilığıyla sağlanır. Kültürel miras da ancak yeni nesillere aktarılarak geleceğe taşınabilir. Bu bakımdan eğitimde somut ve somut olmayan kültürel miras unsurlarına gereken önem verilmeli ve yeni nesiller bu bağlamda yetiştirilmelidir.

"Somut olmayan kültürel miras" terimi, UNESCO'nun "kültürel mirasın korunması" için gerçekleştirdiği çalışmalarda ortaya çıkmıştır. "Somut olmayan kültürel miras"ı, UNESCO; toplulukların ve bireylerin, kültürel miraslarının bir parçası olarak gördükleri uygulamalar, anlatımlar, beceriler ve kültürel mekânlar şeklinde tanımlamaktadır (UNESCO, 2003). Logan (2007, s. 36) da somut olmayan kültürel miras1 "cansiz nesneler yerine insanlarda anlam bulan miras" biçiminde ifade etmektedir. Foley (2014) UNESCO'nun, 1970'lerden beri insanlığın somut olmayan kültürel mirasını koruma üzerine çalışmalar yaptığını belirtir.

Somut Olmayan Kültürel Mirasın (SOKÜM) Korunması Sözleşmesi (2003) ile somut olmayan kültürel mirasın içeriği ortaya koyulmuştur. Sözleşme'de (2003, s. 49) sözlü ve somut olmayan kültürel miras yapıtları aşağıdaki başlıklar altında sınıflandırılmıştır:

1. Dilin Somut Olmayan Kültürel Mirasın Aktarılmasında Bir Araç İşlevi Gördüğü Sözlü Anlatımlar ve Sözlü Gelenekler

2. Gösteri Sanatları

3. Toplumsal Uygulamalar, Ritüeller, Festivaller

4. Halk Bilgisi, Evren ve Doğa İle İlgili Uygulamalar

5. El Sanatları Geleneği

UNESCO'nun 32. Genel Konferansi'nın 17 Ekim 2003 tarihli Genel Kurulu'nda kabul edilen Somut Olmayan Kültürel Mirasın Korunması Sözleşmesi Türkiye'de 2006 yılında yürürlüğe girmiştir. Türkiye sözleşmeyi 45. ülke olarak kabul etmiştir. Sözleşmenin Türkiye'deki icracı kurumu, görev ve sorumlulukları itibariyle T.C. Kültür ve Turizm Bakanlığı Araştırma ve Eğitim Genel Müdürlüğü olarak tayin edilmiştir. Türkiye, 2006-2010 yılları arasında SOKUM Sözleşmesi Hükümetlerarası Komite üyeliğine seçilmiş, 2008-2010 yılları arasında İnsanlı̆̆ın Somut Olmayan Kültürel Mirası Temsilî Listesi'ne Taraf Devletlerce önerilen dosyaları raporlandıran Alt Organda görev yapmıştır. Türkiye, kendi Ulusal Envanter sistemini kurarak ve dosya hazırlama süreçlerini oluşturarak Âşıklık Geleneği (2009), Karagöz (2009), Geleneksel Sohbet Toplantıları (2010), Alevi-Bektaşi Ritüeli Semah (2010), Geleneksel Tören Keşkeği (2011) ve Mesir Macunu Festivali (2012) gibi somut olmayan kültürel miras unsurlarının Temsilî Liste'ye yazılmasını sağlamıştır (Kültür ve Turizm Bakanlığı, 2013).

Türkiye'de korunması gereken sayısız insanlık mirası yeni çalışmalar yapılmasını beklemektedir. Bu zengin birikimi oluşturan coğrafyanın "somut olmayan" kültürel mirasının da korunması ve gelecek kuşaklara aktarılması büyük önem taşımaktadır (Oğuz, 2013, s. 65).

Ashworth, Graham ve Tunbridge (2007, s. 78) ile Howard (2003, s. 31), kültürel mirasın; kimlik oluşturması, sanatsal, tarihi ve bilimsel değer taşıması bakımından korunması gerektiğinin altını çizer. Kültürel miras bir toplumun kültürel kimliğini oluşturduğu için toplumun devamını sağlar ve topluma aidiyet duygusu sağlar. Bu 
bakımdan kültürel miras kavramı kültürel hakların korunması ve kuşaklar arası bağın güçlendirilmesinde önemli toplumsal işlevlere sahiptir. Bu noktada en önemli görev eğitime düşmektedir.

Ekici (2004, s. 9), somut olmayan kültürel mirasın korunmasında bu mirasın "sürdürülebilir" kılınmasının önemine dikkat çeker. Bu da bu mirasın yeni nesillere aktarılmasının önemini göstermektedir. Bu nedenle eğitim sistemleri aracılığıyla kültürel mirası korumak için farkındalık oluşturulması elzemdir. Börekçi (1999, s. 534), toplumların deneyimlerinin ancak yeni nesillere aktarıldığında kültüre dönüştüğünü belirtir ve bu aktarımın da dil vasıtasıyla olacağına dikkat çeker. Benzer biçimde Başgöz (1999, s. 65) de kültür aktarımında eğitimin önemine vurgu yapar. 2010 yılında Türkiye'de gerçekleştirilen Somut Olmayan Kültürel Mirasın Yaygın ve Örgün Eğitimde Değerlendirilmesi Uluslararası Toplantısında dünyada bu sorunsala cevap bulma çalışmalarında Türkiye öncü bir rol üstlenmiş ve kültürel mirasın hak ettiği değeri bulmasında eğitimin yerine dikkat çekmiştir. Çünkü ancak eğitim aracılığı ile somut olmayan kültürel miras unsurları gelecek nesillere aktarılabilir. Nitelikli bir eğitim sayesinde bireyler somut olmayan kültürel miras unrularının önemini kavrar ve onlara hak ettikleri değeri verir.

Akhan (2014, s. 726), Türkiye'de örgün eğitimde kültürel miras eğitiminin en çok Sosyal Bilgiler, Türk Dili ve Edebiyatı, Tarih ve Türkçe derslerinde verildiğini ifade eder. UNESCO'nun, hazırladığı somut olmayan kültürel miras listelerinin yanı sıra ülkemizde Kültür ve Turizm Bakanlığının çalışmaları çerçevesinde de envanterler oluşturulmuştur. Bir unsurun UNESCO SOKÜM Listelerine kayıt edilebilmesi için başvuruda bulunan ülkenin o unsuru ulusal envanterine kayıt etmesi zorunludur (https://ich.unesco.org/en/procedure-ofinscription-00809). UNESCO'nun SOKÜM listelerinde Türkiye'ye ait 18 unsur yer alırken Kültür ve Turizm Bakanlığının ulusal envanterinde 114 unsur yer almaktadır. Okullardaki eğitim ve öğretimin esas görevi kültürün kuşaklara aktarılmasını ve devamını sağlamaktır. $\mathrm{Bu}$ nedenle, Türkçe ders kitaplarında somut olmayan kültürel mirasın yeterli şekilde aktarılması büyük önem taşımaktadır.

Somut olmayan kültürel mirasın çocuklara aktarılmasında edebî eserlerden ve ders kitaplarından yararlanmak gerekmektedir. Alan yazında hem Unesco'nun SOKÜM listeleri hem de Kültür ve Turizm Bakanlığının ulusal envanterini birlikte ele alarak ders kitaplarında bu somut olmayan kültürel miras unsurlarını belirlemeye çalışan başka bir çalışmaya rastlanmamıştır. Bu bağlamda kültürün aktarıcısı olan ve eğitimde ana materyal olan 5. ve 7. Türkçe ders kitaplarında somut olmayan kültürel miras unsurlarına ne kadar yer verildiğinin belirlenmesi bu araştırmanın amacını oluşturmaktadır.

\section{YÖNTEM}

\section{Verilerin Toplanması}

5. ve 7. sınıf Türkçe ders kitaplarındaki somut olmayan kültürel miras unsurlarını belirlemeyi amaçlayan bu araştırmada doküman incelemesi yöntemi kullanılmıştır. Nitel araştırmalarda doküman analizi gibi nitel veri toplama yöntemlerinde algilar ile olaylar bütüncül bir şekilde ortaya konulur (Yıldırım ve Şimşek, 2013, s. 74).

Araştırmada UNESCO listeleri ve Kültür Bakanlığının somut olmayan kültürel miras ulusal envanteri kapsamında 5. ve 7. sınıf Türkçe ders kitapları incelenmiş ve veriler değerlendirilmiştir. 


\section{Çalışma Materyalleri}

Bu araştırmanın materyallerini 5. ve 7. sınıf Türkçe ders kitapları oluşturmaktadır. Ders kitaplarındaki toplam kırk metin ve etkinliklerin tamamında somut olmayan kültürel miras unsurları aranmıştır.

\section{Verilerin Analizi}

Araştırmada 5. ve 7. sınıf Türkçe ders kitaplarındaki metinler ve etkinlikler incelenmiş ve Türkçe ders kitaplarındaki metin ve etkinliklerden doğrudan alıntılar yapılmıştır. İncelenen metin ve etkinliklerde somut olmayan kültürel miras alanlarıla ilgili bir ögenin yer alması ölçüt olarak belirlenmiştir. Araştırmanın güvenirliği için de bir alan uzmanından verileri değerlendirmesi istenmiştir.

\section{BULGULAR}

Tablo 1. UNESCO ile Kültür ve Turizm Bakanlığının ulusal envanterlerinde yer alan somut olmayan kültürel miras unsurları

\begin{tabular}{|c|c|c|c|c|}
\hline \multirow[t]{3}{*}{$\begin{array}{l}\text { Envanterlerinde ve } \\
\text { Her İki Sınıf } \\
\text { Kitabında Yer Alan } \\
\text { Unsurlar }\end{array}$} & $\begin{array}{c}\text { UNESCO ile } \\
\text { Kültür ve Turizm } \\
\text { Bakanlığının } \\
\text { Ulusal } \\
\text { Envanterlerinde ve } \\
\text { Sadece 5. Sınıfta } \\
\text { Yer Alan Unsurlar }\end{array}$ & $\begin{array}{c}\text { UNESCO ile } \\
\text { Kültür ve Turizm } \\
\text { Bakanlığının } \\
\text { Ulusal } \\
\text { Envanterlerinde ve } \\
\text { Sadece 7. Sınıfta } \\
\text { Yer Alan Unsurlar }\end{array}$ & $\begin{array}{l}\text { Sadece Kültür ve } \\
\text { Turizm } \\
\text { Bakanlığının } \\
\text { Ulusal } \\
\text { Envanterlerinde ve } \\
\text { Sadece 5. Sınıfta } \\
\text { Olan Unsurlar }\end{array}$ & $\begin{array}{c}\text { Sadece Kültür ve } \\
\text { Turizm } \\
\text { Bakanlığının } \\
\text { Ulusal } \\
\text { Envanterlerinde } \\
\text { ve Sadece } 7 . \\
\text { Sinifta Olan } \\
\text { Unsurlar }\end{array}$ \\
\hline & $\begin{array}{l}\text { Alevi-Bektaşi } \\
\text { Ritüeli Semah }\end{array}$ & $\begin{array}{l}\text { Ebru: Türk Kâğıt } \\
\text { Süsleme Sanatı }\end{array}$ & Aşık Oyunu & Imece \\
\hline & $\hat{A}$ şıklık Geleneği & $\begin{array}{l}\text { Bahar Kutlaması: } \\
\text { Hıdrellez }\end{array}$ & Horon & \\
\hline Karagöz & $\begin{array}{l}\text { Geleneksel Çini } \\
\text { Ustalığı }\end{array}$ & & Cirit & \\
\hline
\end{tabular}

Kırkpinar Yağll

Güreş Festivali

Dede Korkut

Mirasi: Destan,

Masal ve Müzik

Türk Kahvesi

Kültürü ve

Geleneğ $i$

Tablo incelendiğinde UNESCO ile Kültür ve Turizm Bakanlığının ulusal envanterlerinde yer alan somut olmayan kültürel miras unsurlarına ders kitaplarında çok sınırlı biçimde yer verildiği görülmektedir.

UNESCO ile Kültür ve Turizm Bakanlığının Ulusal Envanterlerinde ve Her İki Sınıf Kitabında Yer Alan Somut Olmayan Kültürel Miras Unsurlarına Örnekler:

\section{Karagöz:}

"Karagöz, sanatçının performansına dayalı bir gölge oyunu olup Karagöz ve Hacivat arasında geçen karşılıklı, komik diyaloglar ve atışmalara dayanır." (5. Sınıf, s. 85) 
Karagöz ve Hacivat maceralarını izlemek bizler için biraz uzak ama kahvehaneler hâlâ toplumsal yaşamın temel mekânlarından birini oluşturmaktadır. (7. Sınıf, s. 95)

\section{Kırkpınar yağlı güreş festivali:}

“O kadar maceradan sonra nihayet Edirne'ye vardık. Dedem yolu bildiği için Kırkpınar Yağlı Güreşleri'nin yapıldığı alanı bulmakta zorlanmadık." (5. Sınıf, s. 211)

"Kırkpınar güreşleri haziran ayının ortalarında yapılır." (7. Sınıf, s. 247)

Dede Korkut mirası: destan, masal ve müzik:

"Dede Korkut, Dirse Han'ın oğluna isim verdikten sonra olaylar nasıl gelişmiş olabilir?" (5. Sinuf, s. 156)

"Bir "Dede Korkut" hikâyesi okuyarak Türklerin yaşayış tarzlarına yönelik notlar alınız." (7. Sınıf, s. 115)

\section{Türk kahvesi kültürü ve geleneği:}

“Keyfine çok düşkün biri olan Affan Efendi'nin dükkânı akşamları sohbete, kahve içmeye gelen memurlarla dolar; bu hâliyle dükkân bir kahvehaneye dönüşürdü." (5. Sınıf, s. 18)

"Türk kahvesinin hazırlanışı ve sunumunu" aile büyüklerinizden veya çoklu medya kaynaklarından yararlanarak araştııınız. (7. Sınıf, s. 87)

UNESCO ile Kültür ve Turizm Bakanlığının Ulusal Envanterlerinde ve Sadece 5. Sınıfta Yer Alan Somut Olmayan Kültürel Miras Unsurlarına Örnekler:

\section{Alevi-Bektaşi Ritüeli Semah:}

“Yunus Emre'den, Mevlana'dan, Hacı Bektaş'tan, Hacı Bayram-1 Veli'den, Pir Sultan Abdal'dan, Koca Sinan'dan beslenen bu toprağın evlatları, zalimlere karşı istiklali ve istikbali için direndi." (5. Sınıf, s. 55-58, 97-98)

\section{Âşıklık Geleneği:}

"Bir ah çeksem dağı taşı eritir,

Gözüm yaşı değirmeni yürütür."

Karacaoğlan (7. Sınıf, s. 31)

\section{Geleneksel Çini Ustalığı:}

“Ülkemizin dört bir yanında Yavrum adsız bir çeşme ol. Görülen iyilik amacıyla yaptırılmış çeşme örneği.

Çinili Çeşme" (5. Sınıf, s. 95)

UNESCO ile Kültür ve Turizm Bakanlığının Ulusal Envanterlerinde ve Sadece 7. Sınıfta Yer Alan Somut Olmayan Kültürel Miras Unsurlarına Örnekler:

Ebru: Türk kâğıt süsleme sanatı:

“Ebru sanatı ilk olarak Orta Asya'da ortaya çıkmıştır." (7. Sınıf, s. 254)

\section{Bahar Kutlaması: Hidrellez:}

"Bayram sabahlarını, Hıdırellez günlerini, kuyuların işleyip işlemediklerini, akranlarını, evleri, sokakları, bazı belli başlı ağaçları soruyor; bunlarla ilgili en ayrıntılı bilgileri öğrenmek istiyordu." (7. Sınıf, s. 121) 
Sadece Kültür ve Turizm Bakanlığının Ulusal Envanterlerinde ve Sadece 5. Sınıfta Yer Alan Somut Olmayan Kültürel Miras Unsurlarına Örnekler:

\section{Aşık oyunu:}

"Aşık oynardım. Hani şu koyunların bacaklarından çıkan kemik var ya, işte onunla. Aşı̆̆ı kırmızı, çıkmaz boyaya boyardım. (5. Sınıf, s. 11-12)

\section{Horon:}

Folklorik bir halay türü olan horon, kemençe müziği eşliğinde oynanır. (5. Sınıf, s. 147)

\section{Cirit:}

"Anadolu'nun geleneksel seyirlik oyunları arasında cirit oyunlarının yeri büyüktür. Cirit oyunları, bir eğlence, bir yiğitlik ve çeviklik gösterisi, aynı zamanda bir atlı spordur." (5. Sinif, s. 194)

Sadece Kültür ve Turizm Bakanlığının Ulusal Envanterlerinde ve Sadece 7. Sınıfta Olan Somut Olmayan Kültürel Miras Unsurlarına Örnekler:

İmece:

“İmece usulüyle suyun tarlalardan geçirilerek köye ulaştırılması.” (7. Sınıf, s. 236)

\section{UNESCO Listesinde Olup Kitaplarda Yer Verilmeyenler:}

“Meddahlık, Nevruz, Geleneksel Sohbet Toplantıları, Tören Keşkeği Geleneği, Mesir Macunu Festivali, İnce Ekmek Yapma ve Paylaşma Kültürü: Lavaş, Katırma, Jupka, Yufka, Islik Dili"

\section{Kültür ve Turizm Bakanlığının Ulusal Envanterinde Kayıtlı Olup Kitaplarda Yer Verilmeyenler:}

"Meddahlık Geleneği, Nevruz, Barana, Sıra Gecesi, Yâren vb. Geleneksel Sohbet Toplantıları Tören Keşkeği Geleneği, Mesir Macunu Festivali, Nazar Boncuğu Geleneği, Aşure Geleneği, Sabantoy ve Tepreş, Sarıkeçililer ve Yayla Göçü, Islık Dili, Taş İşlemeciliği Geleneği, Ahilik, Arguvan Türküleri, Atma Türkü Geleneği, Barak Havaları, Bıçakçılık Geleneği, Boğaz Havaları, Bozlak Havaları, Cam Altı Resmi, Halı Dokuma Geleneği, Hayır Geleneği, Kaşenlik, Keçecilik Geleneği, Kilim Dokuma Geleneği, Kirvelik, Kispet Yapımcılığı, Köçeklik, Köroğlu Hikâyelerini Anlatma Geleneği, Köse Oyunu, Lületaşı İşleme Sanatı, Mayıs Yedisi, Yazmacılık Geleneği, Zeybeklik Geleneği, Ahşap Oymacılığı, Oya Sanatı, Sepetçilik Geleneği, Seğmenlik Geleneği, Sinsin Oyunu, Telkâri Sanatı, Yağmur Duası Törenleri, Arabaşı Geleneği, Çalgı Yapımcılığı, Çoban Bayramları:Koç Katımı, Saya, Döl Dökümü, Yünüm-Koyun Yüzdürme, Aşuk ve Maşuk, Bakırcılık Geleneği, Bar, Bastonculuk Geleneği, Cezayir Havaları, Çömlekçilik Geleneği, Edirnekâri Sanatı, Erguvan Bayramı, Ehram Geleneği, Çeyiz Geleneği, Çiğdem Pilavı, Değirmen Kültürü, Deve Oyunu, Diş Hediği Geleneği, Hat Sanatı , Hoyrat, İpek ve İpek Böcekçiliği Kültürü, Kanaviçe İşleme Geleneği, Karşılama, Katı' Sanatı, Kına Gecesi, Kız Kaçırma Oyunu, Kukla, Kündekâri Sanatı, Macahel Şarkı Söyleme Geleneği, Mâni Söyleme Geleneği, Minyatür Sanatı, Ninni Söyleme Geleneği, Ölü Helvası Geleneği, Pekmez ve Şıra Yapımı, Saraçlık Geleneği, Sedef Kakma Sanatı, Şivlilik Geleneği, Talikacılık, Taziye Geleneği, Tezhip Sanatı, Topaç, Üfleme Cam ve Beykoz İşi Süsleme Sanatı, Yemenicilik Geleneği, Yorgancılık Geleneği, Zeytin ve Zeytinyağı Kültürü, İnce Ekmek Geleneği: Yufka ve Lavaş, Mersiye Geleneği, Mevlit 
Geleneği, Lokum Kültürü, Tahta Kaşık Geleneği, Geleneksel Zekâ ve Strateji Oyunu: Mangala/Göçürme, Geleneksel Mey Zanatkarlığı ve İcracılığı, Çay Kültürü."

\section{TARTIŞMA}

Somut olmayan kültürel mirasın korunması için eğitim sistemlerinin farkındalık oluşturması gerekmektedir. Betimsel özellikteki bu araştırmada 5. ve 7. sınıf Türkçe ders kitapları somut olmayan kültürel miras ögelerine yer verme açısından ele alınmıştır.

UNESCO ile Kültür ve Turizm Bakanlığının ulusal envanterlerinde yer alan ve her iki sınıf kitabında yer alan unsurlar: Karagöz, Kırkpınar Yağlı Güreş Festivali, Dede Korkut Mirasi: Destan, Masal ve Müzik, Türk Kahvesi Kültürü ve Geleneği'dir. UNESCO ve Kültür ve Turizm Bakanlığının Ulusal Envanterlerinde ve sadece 5. Sınıfta yer alan unsurlar: AleviBektaşi Ritüeli Semah, Âşıklık Geleneği ve Geleneksel Çini Ustalığı'dır. UNESCO ile Kültür ve Turizm Bakanlığının ulusal envanterlerinde ve sadece 7. Sınıfta yer alan unsurlar: Ebru: Türk Kâğıt Süsleme Sanatı, Bahar Kutlaması: Hıdrellez'dir. Sadece Kültür ve Turizm Bakanlığının Ulusal Envanterlerinde yer alan ve sadece 5. Sınıfta olan unsurlar: Aşık Oyunu, Horon, Cirit'tir. Sadece Kültür ve Turizm Bakanlığının ulusal envanterlerinde yer alan ve sadece 7. Sinıfta olan unsur ise İmece'dir.

UNESCO listelerinde olup kitaplarda yer verilmeyenler ise "Mevlevi Sema Töreni, Meddahlık, Nevruz, Geleneksel Sohbet Toplantıları, Geleneksel Türk Okçuluğu, Tören Keşkeği Geleneği, Mesir Macunu Festivali, İnce Ekmek Yapma ve Paylaşma Kültürü: Lavaş, Katırma, Jupka, Yufka, Islık Dili'dir.

Kültür ve Turizm Bakanlığının ulusal envanterlerinde olan ancak Türkçe ders kitaplarda yer verilmeyen doksan üç somut olmayan kültürel miras unsuru tespit edilmiştir. Savaşkan'ın (2016) Türk Edebiyatı ders kitaplarını incelediği araştırmasında da bu araştırmaya benzer şekilde somut olmayan kültürel miras unsurlarına kitaplarda yeterince yer verilmediği bulgusuna ulaşılmıştır. Kolaç'ın (2009) çalışmasında da Türkçe ders kitaplarında Karagöz, geleneksel Türk süsleme sanatları, geleneksel seyirlik oyunlar, Hıdırellez, Nevruz gibi somut olmayan kültür ögelerine yer verildiği diğerlerinin ihmal edildiği belirlenmiştir. Bu veriler, Dede Korkut ve Karagöz dışında, ders kitaplarında yer verilenlerin önemli bir bölümünün somut olmayan kültürel unsurlarla ilgili yüzeysel bilgileri içerdiğini ve çoğunun metinlerde yapılan kısa atıflardan ibaret olduğunu göstermektedir. Bu durum Dede Korkut ve Karagöz'de olduğu gibi Türkçe ders kitaplarında somut olmayan kültür değerlerine yönelik bilinç ve farkındalığı arttıracak, düzeye uygun etkinliklere yer verilmesi ve Türkçe ders kitapları somut olmayan kültür değerleriyle ilgili daha fazla ifadeler içeren metinlerle zenginleştirilmesi gereği ifade edilebilir. Alan yazındaki çalışmalar (Alkış ve Oğuzoğlu, 2005; Copeland; 2004; Curtis ve Seymour, 2004; Foley, 2014; Hereduc, 2005; Yücel, 2006) kültürel mirasın korunmasında eğitimin önemine vurgu yapmaktadır. Bu bakımdan Türkçe ders kitaplarında somut olmayan kültürel miras unsurlarına daha fazla yer verilmeli ve etkinlikler de bu bağlamda artırılmalıdır.

Yeşilbursa'nın (2013) araştırmasında öğrencilerin kültürel eserleri önemli bir bilgi kaynağ1 olarak gördükleri belirlenmiştir. Kültürel mirasa yönelik eğitimlerin olumlu tutum geliştirmeye etkisini inceleyen araştırmalarda (Curtis ve Seymour, 2004; Dönmez ve Yeşilbursa 2014) yapılan etkinliklerin öğrencilerin somut kültürel mirasa yönelik tutumlarını geliştirmede etkili olduğu sonucuna ulaşılmıştır. Aslan ve Ardemagni'nin (2002), araştırmasında da miras eğitimiyle öğrencilerin kültürel mirası korumanın onların 
sorumluluğu olduklarının farkına vardıkları belirlenmiştir. Eğitimde kullanılan ana materyal ders kitapları olduğu için özellikle somut olmayan kültürel mirasın yeni nesillere aktarılmasında kitaplar büyük önem taşımaktadır. Bu bakımdan ders kitaplarında somut olmayan kültürel miras unsurlarına daha fazla yer verilmeli ve öğrencilerin bu değerleri içselleştirmelerine yardımcı olunmalıdır.

Gimenez, Guiz ve Listan'ın (2008), araştırmalarında kültürel miras eğitiminin sosyodoğal çevre hakkında eleştirel düşünmeyi desteklediğini tespit etmişlerdir. Wilhelm, (2004) da kültürel miras eğitiminin derslerle bağlantılı olarak verilmesi gerektiğini belirtmiştir. Bu bağlamda ders kitaplarında kültürel miras unsurlarına yeterince yer verilmesi gereği ortadadır. Ders kitaplarına seçilecek metinlerde somut olmayan kültürel miras unsurlarına yer verilmesine özen gösterilmeli, derslerde de bu unsurların önemini kavratacak etkinlikler yapılmalıdır. Kasapoğlu Akyol (2016) da okullarda gerçekleştirilecek somut olmayan kültürel miras eğitiminde öğrencilerin daha fazla ilgisini çeken ve kalıcı öğrenmenin gerçekleşmesine yardımcı olan uygulamalara dikkat çeker. Bu da ancak ders kitaplarında somut olmayan kültürel miras unsurlarına yer veren nitelikli metinler ve etkinliklerle elde edilebilecektir.

Dönmez ve Yeşilbursa'nın (2014) araştırmasında kültürel miras eğitiminin öğrencilerin kültürel mirasa karşı olumlu tutum geliştirmelerinde rol oynadığ belirlenmiş̧tir. $\mathrm{Bu}$ bakımdan derslerdeki etkinliklerde kültürel miras unsurlarına yer verilmesi önem taşımaktadır. Gürçayır Teke (2013) de sözleşmenin başarıya ulaşmasının eğitim konusunda elde edilecek başarılarla paralellikler göstereceğine dikkat çeker. Somut olmayan kültürel miras unsurlarını öğrenmek eğitimin önemli bir parçası oluşturmaktadır. Çünkü bireyler somut olmayan kültürel miras unsurlarının önemini kavrayarak onlara gereken değeri verir ve kültürlerinin farkına vararak geçmiş ve gelecek arasında köprü oluştururlar. Bu bağlamda somut olmayan kültürel miras unsurlarının eğitimle olan ayrılmaz ilişkisi göz önüne alınmalı ve Türkçe ders kitapları bu unsurlar bakımından zenginleştirilmelidir.

\section{SONUÇ VE ÖNERILER}

Araştırma bulgularına göre 7. Sınıf Türkçe ders kitabında 5. Sınıf ders kitabına kıyasla daha az somut olmayan kültürel miras unsuruna yer verildiği belirlenmiştir. Kültürel mirasın her sınıf düzeyinde önemli olmasından hareketle özellikle 7. Sınıf Türkçe ders kitabı bu bakımdan zenginleştirilmelidir. Sonuç olarak Türkçe dersinin kültürel unsurlarla sıkı bir ilişki içinde olduğu unutulmamalı ve bu sebeple Türkçe ders kitaplarındaki metinlerde ve etkinliklerde somut olmayan kültürel miras unsurlarına hak ettiği yer verilmelidir.

Türkçe ders kitaplarında somut olmayan kültür değerlerine yönelik farkındalığı arttıracak etkinliklere yer verilmesi ve Türkçe ders kitaplarının somut olmayan kültür değerleriyle ilgili metinlerle zenginleştirilmesi gerekmektedir. Ayrıca somut kültürel mirasın korunması için farklı düzeydeki ders kitapları da incelenmeli ve bu kitaplardaki somut olmayan kültürel miras unsurları tespit edilmelidir. Çünkü ders kitapları eğitimdeki ana materyallerdendir ve bu materyallerde toplumun en önemli unsurlarından olan somut olmayan kültürel miras unsurlarının ne derece yer aldığının belirlenmesi önemlidir. Çünkü ancak eğitim aracılığıyla bireylerin somut olmayan kültürel miras unsurlarına gereken değeri vermeleri sağlanabilir. Ayrıca eğitimin uygulayıcıları olan öğretmenlerin somut olmayan kültürel mirasın eğitimine yönelik yeterliklerini ve görüşlerini belirlemeye yönelik 
çalışmalar ile öğretim programlarında somut olmayan kültürel mirasın ne ölçüde yer aldığının belirlendiği çalışmaların yapılması da önem taşımaktadır.

\section{SUMMARY}

The term "intangible cultural heritage" emerged during the programs conducted by UNESCO for "the safeguarding of cultural heritage". With its approaches that have been clarified in both the convention and the following studies, UNESCO visualises intangible cultural heritage as the common memory of primarily the society that creates and safeguards it and then the whole humanity.

Safeguarding of intangible cultural heritage would be possible by making this heritage sustainable. Thus, it is necessary to transmit intangible cultural heritage to young generations. Raising young generation's awareness that today intangible cultural heritage has a constant worth plays a key role in the safeguarding and sustainability of this heritage. Therefore, educational systems should show the young generations the significance of cultural heritages and create awareness to safeguard cultural heritage.

Stating from this point, the main purpose of this study is to investigate the elements of intangible cultural heritage included in Turkish language course books of grades 5 and 7 . This study which tries to determine whether Turkish language course books (grade 5 and grade 7) fulfil the duty that they take is a qualitative research, and it has been evaluated using the document review method. The reliability formula suggested by Miles and Huberman was used to calculate the reliability of the research. When the researcher and the field expert agreed, it was decided that the process of reliability ended.

In the research, the texts included in Turkish language course boks (grades 5 and 7) were examined one by one, and the obtained findings were presented in tables with their frequencies. When it was necessary, the findings examined in the research were directly quoted.

The elements which are inscribed in the UNESCO Intangible Cultural Heritage Lists and Inventories of the Ministry of Culture and Tourism, and included in the course books of both grades are:

The Mevlevi Sema Ceremony, The Kırkpınar Oil Wrestling Festival, The Heritage of Dede Qorqud: Epic Culture, Folk Tales and Music, Turkish Coffee Culture and Tradition.

The elements which are inscribed in the UNESCO Intangible Cultural Heritage Lists and Inventories of the Ministry of Culture and Tourism, and included in only grade 5 are: Alevi-Bektaşi Ritual Semah, The Aşıklık (minstrelsy) Tradition, Traditional craftsmanship of Çini-making. The elements which are inscribed in the UNESCO Intangible Cultural Heritage Lists and Inventories of Ministry of Culture and Tourism, included in only grade 7 are:

Ebru, Turkish art of marbling, The Spring Celebration: Hidrellez. The elements which are only inscribed in the Inventories of Ministry of Culture and Tourism in grade 5 are: Aşık Game, Horon(dance), Jereed. The element which is only inscribed in Inventories of Ministry of Culture and Tourism in grade 7 is: Communal work.

The elements which are inscribed in the UNESCO Intangible Cultural Heritage Lists, but not included in the books are: 
"The Mevlevi Sema ceremony, Arts of the Meddah (The Art of Public Story Telling), Nevruz, Traditional Sohbet meetings, Traditional Turkish Archery, Ceremonial Keşkek Tradition, Mesir Macunu Festival, Flatbread making and sharing culture: Lavash, Katyrma, Jupka, Yufka, Whistled language.

The elements which are inscribed in the Inventories of the Ministry of Culture and Tourism, but not included in the books are: The Arts of the Meddah (public storytellers), Nevruz, Barana, Sira Night, Yaren, etc, Traditional Sohbet Meetings, The Ceremonial Keşkek Tradition, Mesir Macunu Festival, The Evil Eye Bead Tradition, Noah's Pudding Ritual, Sabantoy and Tepreş, Sarıkeçili Yörüks and Upland Movement, Whistled Language, The Stonework Tradition, Ahi Brotherhood, Arguvan Folk Songs, Barak Unmetered Folk Songs, Cutlery Tradition, Boğaz Unmetered Folk Songs, Bozlak Unmetered Folk Songs, Reverse Glass Painting, The Carpet Weaving Tradition, The Tradition of Charity, Kaşenlik, The Tradition of Felt Making, The Rug Weaving Tradition, Kirvelik, Wrestler's Tights Making, Köçeklik(male dancing), The Tradition of Telling the Tales of Köroğlu, The Köse Game, The Art of Meerschaum Craftsmanship, May 7, The Tradition of Block Printing, The Zeybek Tradition, Wood Carving, The Art of Embroidery, The Basket Weaving Tradition, The Seymen Tradition, The Sinsin Game, The Art of Fligree, Prayer Ceremonies for Rain, The Arabaşı Tradition, Instrument-Making, The Shepherd's Bairams: mating of sheep, Saya (100 days after mating of sheep), döl dökümü (giving birth to a lamb), yünüm-koyun yüzdürme (a competition based on a shepherd's skills in making sheep swim across a pond), Aşuk and Maşuk, The Tradition of Copper Craft, Bar(dance), The Tradition of Walking Stick Making, Algerian Unmetered Folk Songs, The Pottery Tradition, The Art of Edirnekari, The Erguvan (Judas-Tree) Bairam, The Tradition of Ehram, Traditional of Dowry, Meadow Saffron Pilaf, The Mill Culture, The Camel Game, The Tradition of Tooth Wheat, Calligraphy, Hoyrat(a kind of mani), The Tradition of Silk and Silkworm-breeding, The Tradition of Cross stitch, Karşılama (dance), The Art of Katı', The Henna night, The Game of Eloping with a Girl, Puppet, The Art of Kündekâri, The Tradition of Macahel Song Singing, The Tradition of Singing a Mâni (a form of Turkish folk song in quatrains), The Miniature Craft, The Tradition of Lullaby Singing, The Tradition of Halva of the Dead, Molasse and Grape Juice Making, The Tradition of Saraçlık, Mother-of-pearl inlaying, The Tradition of Şivrilik, Talika Making, The Tradition of Condolence, Illuminated Manuscript, Peg Top, Glass blowing and Beykoz-Style Decorative Art, Kerchief Making, Quilting, Olive and Olive Oil Culture, Flatbread making: Yufka and Lavash, Marsiya Tradition, The Mevlit Tradition, The Turkish Delight Culture, The Wooden Spoon Making Tradition, Traditional Intelligence and Strategy Game: Mangala/Göçürme, Traditional Craftsmanship and Performing of Mey, The Tea Culture.

In reference to the findings, it can be expressed that it is necessary to include activities that raise consciousness and awareness of intangible cultural values in Turkish language course books, and to enrich Turkish language course books with texts involving more expressions related to intangible cultural values.

Originally, it is certain that language and literature courses learned at school are tightly associated with the development of a culture. Therefore, it should be known that literary works used in courses are not things belonging to a simple genre, and courses should be taught by considering the fact that they have effects, which continue for ages, and sociological, historical, cultural dimensions.

SEFAD, 2020; (44): 295-308 
Makale Bilgileri

Etik Kurul Karart:

Etik Kurul Kararından muaftır.

Katılımcı Rızası:

Katılimci yoktur

Mali Destek:

Çalışma için herhangi bir kurum ve projeden mali destek alınmamıştır.

Çıkar Çatışması: Çalışmada kişiler ve kurumlar arası çıkar çatışması bulunmamaktadır.

Telif Haklart:

Telif hakkına sebep olacak bir materyal kullanılmamıştır.

Article Information

Ethics Committee Approval: $\quad$ It is exempt from the Ethics Committee Approval.

Informed Consent:

No participants

Financial Support:

The study received no financial support from any institution or project.

Conflict of Interest:

The authors declare that declare no conflict of interest.

Copyrights:

No material subject to copyright is included. 


\section{KAYNAKÇA}

Akhan, N. E. (2014). Sosyal bilgiler derslerinde somut olmayan kültürel miras öğretimi. International Online Journal of Educational Sciences, 6(3), 722-736.

Alkış, S. \& Oğuzoğlu, Y. (2005). Ülkemiz koşullarında tarihi çevre eğitiminin önemini ve gerekliliğini artıran nedenler. Uludağ Üniversitesi Eğitim Fakültesi Dergisi, 18(2), 347-361.

Artun, E. (2000). Halk kültürü ve folklorun Türk kültüründeki yerine kültürel değişim ve gelişim açısından bakış. Adana: Halk Kültürü Araştırmaları.

Ashworth, G.J., Graham, B. \& Tunbridge, J.E. (2007). Pluralising pasts: Heritage, identity and place in multicultural societies. London: Pluto Press.

Aslan, Z., \& Ardemagni, M. (2006). Introducing young people to the protection of heritage sites and historic cites. Erişim adresi: http://www.iccrom.org.

Bağcl, A.(2016). Somut olmayan kültürel mirasın aktifleştirilmesi problemi. Karatekin Edebiyat Fakültesi Dergisi (KAREFAD), 4(2), 167-173.

Başgöz, İ. (1999). Türkiye'nin eğitim çıkmazı ve Atatürk. Ankara: Kültür Bakanlığı Yayınları.

Börekçi, M. (1999). Kültür-dil-edebiyat bağlamında Türk kültürü-Türkçe ve Türk edebiyatı. Türk Dili, 570, 532-538.

Copeland, T. (2004). Heritage and education: A European perspective. The Hague Forum 2004 (pp. 18-22). Erişim adresi: http://www.europanostra.org/documents.

Curtis, R. \& Seymour, C. (2004). Louisiana heritage education program and heritage in the classroom: children's attitudes toward cultural heritage. Journal of Social Studies Research, 28(2), 20-24.

Dönmez, C., \& Yeşilbursa, C. C. (2014). Kültürel miras eğitiminin öğrencilerin somut kültürel mirasa yönelik tutumlarına etkisi. Elementary Education Online, 13(2), 425-442.

Ekici, M. (2004). Bir sempozyumun ardından: somut olmayan kültürel mirasın müzelenmesi. Millî Folklor, 16(61), 5-13.

Foley, K. (2014). No more masterpieces: tangible impacts and intangible cultural heritage in bordered worlds. Asian Theatre Journal, 31(2), 369-398.

Gimenez, J.E., Ruiz, R.M.A. \& Listan, M.F. (2008). Primary and secondary teachers' conceptions about heritage and heritage education: A comparative analysis. Teacher and Teacher Education, 24, 2095-2107.

Girard, F. (2017). "Yaşayan insan hazineleri" ulusal sistemlerin kurulmasına ilişkin $\begin{array}{lllll}\text { kılavuzlar ilkeler } & \text { (N. İçöz, Çev.). Erişim adresi: }\end{array}$ http://www.unesco.org.tr/dokumanlar/somut_olmayan_km/UNESCOYIH.pdf.

Gürçayır Teke, S. (2013). Geleneksel tarzlar, modern modeller: resmî, resmî olmayan eğitim ve somut olmayan kültürel miras. Millî Folklor, 25(100), 31-39.

Gürçayır, S. (2011). Somut olmayan kültürel mirasın korunması sözleşmesi üzerine eleştirel bir okuma. Milli Folklor, 23(92), 5-12.

Hereduc, A. (2005). Heritage in the classroom: A practical manuel for teachers. Erişim adresi: http://www.hereduc.net/hereduc.

Howard, P. (2003). Heritage: Management, interpretation, identity. New York: Continuum.

Kasapoğlu Akyol, P. (2016). Somut olmayan kültürel mirasın örgün eğitime uygulanması: Ağaraştırması (webquest) örneği. Millî Folklor, 28(111), 125-146. 
Kolaç, E. (2009). Somut olmayan kültürel mirası koruma, bilinç ve duyarlılık oluşturmada Türkçe eğitiminin önemi. Milli Folklor, 21(82), 19-31.

Kurin, R. (2004). Safeguarding Intangible Cultural Heritage in the 2003 UNESCO Convention: a Critical Appraisal. Museum international, 56(1-2), 66-77.

Kültür ve Turizm Bakanlı̆̆ (2013). Gelenekten geleceğe: Türkiye'de somut olmayan kültürel miras. Ankara: Kültür ve Turizm Bakanlığı Yayınları.

Logan, W. (2007). Closing Pandora's Box: Human rights conundrums in cultural heritage protection. In H. Silverman and D. F. Ruggles (Eds.), Cultural heritage and human rights (pp.33-52). New York: Springer.

Oğuz, M. Ö. (2008b). UNESCO ve insanlığın sözlü ve somut olmayan mirası başyapıtları. Millî Folklor, 20(78), 5-11.

Oğuz, Ö. (2007). UNSECO, Kültür ve Türkiye. Milli Folklor, 73, 5-11.

Oğuz, Ö. (2008). UNESCO ve geleneğin ustaları. Milli Folklor, 20(72), 5-10.

Oğuz, Ö. (2013). Somut olmayan kültürel miras nedir? Ankara: Geleneksel Yayıncılık.

SOKÜMKTB (2003). Somut olmayan kültürel mirasın korunması temel belgeler. Ankara: Kültür ve Turizm Bakanlığ 1 Yayınları.

Somut Olmayan Kültürel Mirasın Yaygın ve Örgün Eğitimde Değerlendirilmesi Uluslararası Toplantısı Sonuç Bildirisi, 16-17 Eylül 2010/Antalya-Türkiye.

Şavaşkan, V. (2016). Ortaöğretim Türk edebiyatı program ve ders kitaplarının somut olmayan kültürel miras ögeleri açısından incelenmesi. Erzincan Üniversitesi Eğitim Fakültesi Dergisi, 18(2), 1302-1323.

UNESCO (2003). Somut Olmayan Kültürel Mirasın Korunması Sözleşmesi. Paris.

UNESCO (2017). Procedure of inscription of elements on the Lists and of selection of Good Safeguarding Practices. Erişim adresi: https://ich.unesco.org/en/procedure-of-inscription00809.

Wilhelm, N. (2004). Voyage to the heart of the heritage: Our heritage explained to children. Heritage and education: A European Perspective. Erişim adresi: http://www.europanostra.org/documents.

Yeşilbursa, C. C. (2013). Altıncı sınıf öğrencilerinin somut kültürel mirasa yönelik görüşleri, Kastamonu Eğitim Dergisi. 21(2), 405-420.

Yıldırım, A. \& Şimşek, H. (2011). Nitel araştırma yöntemleri. Ankara: Seçkin Yayıncılık.

Yücel, E. (2006). Kültür varlıklarından korumacılık ve Türkiye gerçeği. Yapı Dergisi, 294, 112116.

\section{İncelenen Kitaplar:}

Ağın Haykır H., Kaplan H., Kıryar A., Tarakcı R. \& Üstün E. (2018). Ortaokul ve imam hatip ortaokulu Türkçe 5 ders kitabı. Ankara: MEB Yayınları.

Akgül A., Demirer N., Gürcan, E., Karadaş, D., Karahan İ. \& Özdemir D. (2018). Ortaokul ve imam hatip ortaokulu Türkçe 7 ders kitabı. Ankara: MEB Yayınları. 